EXTENDED REPORT

\title{
Quantitative evaluation of the corneal endothelium in the mouse after grafting
}

\author{
J Plskova, L Kuffova, M Filipec, V Holan, J V Forrester
}

Br J Ophthalmol 2004;88:1209-1216. doi: 10.1136/bjo.2003.038703

See end of article for authors' affiliations

.....................

Correspondence to: Professor J V Forrester, Department of Ophthalmology, Medical School, University of Aberdeen, Foresterhill, Aberdeen AB25 2ZD, UK; j.forrester@abdn.ac.uk

Accepted for publication 24 February 2004

\begin{abstract}
Background/aim: Corneal graft survival depends critically on the quality of the endothelium. In this study the authors aimed to evaluate corneal endothelium in mice at different times after transplantation and to correlate endothelial integrity with corneal graft survival.

Methods: Syngeneic and allogeneic corneal grafts at various times (days 0-60) after engraftment were examined in flat mount preparation by confocal microscopy, by evaluating the hexagonal pattern of the endothelial monolayer using actin staining of the cell cortex. Corneas from untreated mice and from mice, who were grafted after removal of draining lymph nodes served as controls.

Results: In control corneas, more than $90 \%$ of the posterior surface was covered by endothelium. Syngeneic grafts were always covered by $54-99 \%$ of endothelium. In contrast, the posterior surface of corneal allografts showed great variation in the degree of endothelial cell coverage (0-98\%). In addition, clinical opacity grading measure was not a reliable predictor of endothelial coverage.

Conclusion: In corneal allografts there is progressive loss of endothelium over time, unlike with syngeneic grafts. However, in the early stages of allograft rejection, the grade of graft opacity does not accurately reflect the degree of endothelial cell coverage. Although corneal opacity grade is considered the main determinant of graft rejection, the data suggest that both the grade of corneal opacity plus a sufficient postgraft time duration ( $>8$ weeks in the mouse) are required for the diagnosis of irreversible graft rejection.
\end{abstract}

O rthotopic corneal allografts are generally accepted at a very high rate in various species. ${ }^{1-4}$ However, the incidence of rejected allografts in long term follow up studies is surprisingly high in both humans and rodents, ${ }^{5-7}$ suggesting that the privileged status of the cornea is not absolute. ${ }^{2568}$ Each cell layer of the cornea has a different role in the allosensitisation of the graft recipient. ${ }^{9}$ Although it was considered that the epithelium was the main barrier to corneal graft acceptance according to some previous studies in mice, ${ }^{9-11}$ it has recently been shown that the endothelium presents the major target of alloimmune rejection of orthotopic corneal allografts. ${ }^{11}$

Irreversible corneal graft rejection is diagnosed when the cornea remains opaque despite treatment. Loss of corneal clarity under these circumstances is usually caused by oedema or water retention by the stroma and epithelium. The endothelium, a single layer of hexagonal cells, which plays a vital part in maintaining the deturgescence of the cornea, is presumed to be permanently lost from the donor graft without recovery/replacement from the host site. Human corneal endothelial cells are cells with limited, if any, proliferative capacity in vivo. In vitro, cell proliferation can be induced by specific growth factors and other substances. ${ }^{12-15}$ In animal models corneal endothelial cell regeneration-that is, proliferation and migration, has been shown to occur mostly in models of corneal wounding-for example, after transcorneal freezing ${ }^{16}{ }^{17}$ or endothelial scraping. ${ }^{18}{ }^{19}$ Corneal endothelial migration ${ }^{20} 21$ and proliferation ${ }^{21}$ have also been demonstrated, although weakly, following syngeneic corneal transplantation. In a separate study Joo et al showed that life extended corneal endothelial cells, when transplanted onto denuded murine corneal Descemet's membrane, survived and remained in situ after syngeneic corneal transplantation without replacement by host cells. ${ }^{22}$

However, there is no evidence that corneal endothelial cell proliferation after orthotopic allogeneic corneal transplantation occurs. In a recent study Hori and Streilein used transgenic mice that express enhanced green fluorescence protein (eGFP) in all nucleated cells to transplant eGFP+ "green" donor corneal grafts to allogeneic and syngeneic wild type recipients and vice versa, and showed that the endothelium of accepted allografts retained significant numbers of donor endothelial cells, with little evidence of replacement of donor endothelium with cells of recipient origin. The endothelium of allografts that were rejected was, on the contrary, completely depleted of their complement of donor derived endothelium. ${ }^{11}$ In our study, we have quantified the changes in the integrity of the corneal endothelial monolayer at various time points after orthotopic allogeneic and syngeneic corneal grafting by analysis of confocal microscopic images of flat mounted corneal specimens. In addition, we have tried to correlate the level of endothelial cell loss with clinical signs of rejection-that is, with corneal opacity alone. We conclude that the grade of corneal graft opacity alone does not consistently reflect graft acceptance as defined in terms of the percentage of remaining healthy endothelium. Only persistence of clinically opaque grafts over a prolonged period ( $>8$ weeks in the mouse) reflects true non-survival of the corneal endothelium. Corneal opacification before this time may reflect endothelial cell dysfunction without actual cell loss, and recovery of function is possible if the alloimmune response can be suppressed.

\section{MATERIALS AND METHODS}

\section{Animals}

Inbred female and male mice of the BALB/C $\left(\mathrm{H}_{2}^{\mathrm{d}}\right)$ and C57BL/10 ( $\left.\mathrm{H}^{\mathrm{b}}{ }^{\mathrm{b}}\right)$ strains, 6-8 weeks old, were obtained from the animal facility at the medical school, University of Aberdeen. The procedures adopted conformed to the regulations

Abbreviations: eGFP, enhanced green fluorescence protein; LNR, lymph node removal; PBS, phosphate buffered saline; PFA, paraformaldehyde; IPA, tissue plasminogen activator 
of the Animal Licence Act (UK) and to the ARVO statement for the use of animals in ophthalmic and vision research.

\section{Technique of corneal transplantation}

The procedure was adapted from the technique described previously ${ }^{23}$ and modified by the authors. ${ }^{24}$ In brief, donor corneas (C57BL/10, $\mathrm{H} 2^{\mathrm{b}}$ or $\mathrm{BALB} / \mathrm{c}, \mathrm{H} 2^{\mathrm{d}}$ mice) $2 \mathrm{~mm}$ in diameter were removed and placed in balanced salt solution. The donor endothelium was protected during dissection by instilling Microvisc (high molecular weight hyaluronic acid) into the anterior chamber. The recipient mice (BALB/c) were anaesthetised by intramuscular injection of a mixture of ketamine (Narkamon 5\%, SPOFA, Prague, Czech Republic) and xylazine (Rometar 2\%, SPOFA) diluted in saline. To dilate the pupil a combination of tropicamide $1 \%$ and phenylephrine $2.5 \%$ drops was used. The recipient right cornea was marked with a $2 \mathrm{~mm}$ trephine and excised using Vannas scissors after penetrating the anterior chamber with a sharp needle. Microvisc was used to maintain the anterior chamber throughout the procedure. The donor graft was sutured into the recipient bed using either a continuous or an interrupted suture (11-0 Mersilene, Ethicon, UK). After the transplantation, antibiotic ointment (Polyfax, Dominion Pharma Ltd, UK) was applied to the eye. Interrupted sutures were removed on day 7 under an operating microscope under general anaesthesia and the antibiotic ointment was applied to the eye. Continuous sutures were not removed.

Some corneas appeared to pass through a phase of transient opacification 10-14 days post-grafting and clear subsequently. This occurred more frequently when the grafts were performed with interrupted sutures than with continuous sutures. ${ }^{7}$ The cause for the transient opacity is not known and therefore for the extended time course study the continuous suture technique was used. The interrupted suture technique was used only for a comparison of endothelial coverage at days 10 and 14 after grafting.

\section{Clinical evaluation of corneal grafts}

Mice were examined every 2-4 days through the operating microscope. Mice with complications such as cataract, prolapse of the iris, infection or haemorrhage were excluded from the study. The degree of opacity of the grafted cornea was used as the indicator of graft rejection. ${ }^{7}$ The grade of opacity was $0-4$, where grafts with grade 2 or higher were considered as rejected (grade 2: iris vessels still distinguishable through an opaque corneal graft). Using these criteria, the rate of corneal graft rejection in this study is as shown in figure 1 .

\section{Procedures for corneal dissection and immunohistological evaluation of endothelium}

In preliminary control experiments, the integrity of the intact cornea and of the ungrafted donor cornea was evaluated. The technique used was adapted from Danjo et al. ${ }^{25}$ Mice were sacrificed by dislocation of the neck. Two methods for fixation were used to ensure absence of technical causes for endothelial cell losses/damage. In the first method, eyes were fixed immediately in situ before enucleation (that is, preexcision of the cornea, termed hereafter "pre-X fixed" corneas) with a drop of $4 \%$ paraformaldehyde (PFA) applied to the cornea for at least 20 minutes. The eyes were then enucleated and immersed in PFA in 96 well plates for at least 2 hours. The corneas were then excised at the limbus with the aid of an operating microscope using a petri dish with a sponge base, to which the eyes were fixed with fine pins.

In the second method, the mice were sacrificed and a $2 \mathrm{~mm}$ disc of cornea excised immediately without previous fixation, using the standard procedure for excision of donor corneas for grafting (see above). The corneas were then fixed

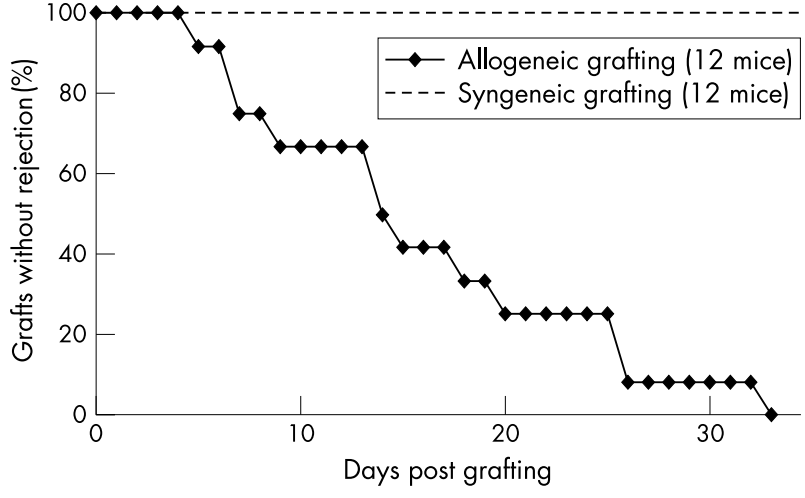

Figure 1 Outcome of corneal grafting. "Survival curves" after syngeneic (BALB/c to $B A L B / C$ ) and allogeneic (C57BL/10 to BALB/c) corneal transplantation in mice, using the continuous suture technique.

by immersion in PFA for at least 2 hours. Since these corneas were fixed after excision (that is, post-excision corneas) they are termed hereafter "post-X fixed" corneas.

Experimental grafted corneas excised and fixed for evaluation of the endothelial monolayer were processed by the first method above- that is, after fixation in situ and by excision of the cornea at the limbus to include the donor cornea and the rim of host cornea as a single specimen (pre- $\mathrm{X}$ fixed corneas).

In both methods, the tissue was then rehydrated in phosphate buffered saline (PBS; three times 10 minutes in the 24 well plate) and the endothelium was stained for actin by Bodipy 558/568 Phalloidin (Molecular Probes UK; dilution 1:20 in PBS; incubated for 2 hours and washed three times 10 minutes by PBS).

Staining of the actin cortex was used to evaluate endothelial cell hexagonal shape and integrity since this has been shown to correlate well with cell shape. ${ }^{26}$

The corneas were dissected into four quadrants using a sharp razor blade, endothelium side up and mounted in Vectashield (Vector Laboratoires, UK) as flat mounts and examined by confocal microscopy. Confocal images were then captured by LaserSharp software (software and microscope by Bio-Rad, UK) at a wavelength of $568 \mathrm{~nm}$.

An additional set of non-rejected clear allograft control grafts was obtained from mice whose submandibular lymph nodes had been removed ${ }^{24}$ before corneal grafting.

The numbers of mice used at each time point are presented in table 1 .

During the course of these experiments, it became clear that significant deposits of fibrinous protein filled the anterior chamber and attached to the posterior surface of the cornea. Accordingly, in some cases (allografts and syngeneic grafts 48 hours to 6 days after grafting) the excised corneas were incubated in tissue plasminogen activator (tPA) (concentration $400 \mathrm{U} / \mathrm{ml}$, in PBS for 5-30 minutes at room temperature) before fixation in order to digest fibrinous material present over the endothelium of the graft. This allowed clear evaluation of the endothelium.

To verify the fibrinous nature of this material, a separate set of grafts were stained with anti-fibrinogen antibody $(\mathrm{Ab})$ (sheep anti-mouse, 1:100, Serotec, UK) with three step immunohistochemistry using secondary Ab anti-sheep biotinylated (1:100) and Streptavidin-Texas Red (1:50). For dilution of $\mathrm{Ab}$ and washing, PBS was used. Corneas were analysed by fluorescence microscopy.

\section{Image analysis}

Images were acquired $(\times 20$ objective $)$ and quantitatively evaluated using Q-Win software (Leica, UK). A microscope 
Table 1 The time points of corneal removal

\begin{tabular}{|c|c|c|c|c|c|c|c|c|c|c|}
\hline Groups of corneas & $\mathrm{Oh}$ & $1 \mathrm{~h}$ & $24 \mathrm{~h}$ & $48 \mathrm{~h}$ & $6 d$ & $10 \mathrm{~d}$ & $14 d$ & $18 d$ & $30 \mathrm{~d}$ & $60 \mathrm{~d}$ \\
\hline Control pre-X fixed corneas & $3^{*}$ & & & & & & & & & \\
\hline Control post- $\mathrm{X}$ fixed corneas & 3 & & & & & & & & & \\
\hline Allografts, continuous suture & & 4 & $x$ & 3 & 3 & 4 & & $x$ & 5 & 4 \\
\hline Allografts, interrupted suture & & & & & & 8 & 5 & & & \\
\hline Syngrafts, continuous suture & & & & 3 & 3 & 2 & & & $x$ & 3 \\
\hline Syngrafts, interrupted suture & & & & & & 4 & 4 & & & \\
\hline Allografts, after LNR & & & & & & & & & & 4 \\
\hline
\end{tabular}

objective of $\times 20$ magnification was chosen because this offered the best image field size for evaluation in a single image. During confocal analysis, the entire cornea was imaged; however, in grafted eyes, only the graft was evaluated quantitatively. Denuded areas of the corneal graft were demarcated on the screen by manual tracking and the area of cell loss expressed as a percentage of the total area of the posterior corneal surface. For each time point, at least three sample corneas were used (unless otherwise indicated).

\section{Technique of lymph node removal}

The technique described by Wolvers ${ }^{27}$ and modified by the authors $^{24}$ was used. In brief, mice were anaesthetised as described above. A small incision in the middle of the headneck region after shaving the skin was made, and with the aid of an operating microscope, the submandibular lymph nodes were removed bilaterally. The wound was closed by three interrupted sutures and cleaned with chlorhexidine and antibiotic. Seven days later corneal grafting was performed.

\section{Statistical analysis}

To compare the percentage of the area covered by endothelium between experimental groups, the Mann-Whitney U test (GraphPad InStat software) was used.

\section{RESULTS}

Quantitative evaluation of endothelial cell integrity at different time points after grafting (continuous suture technique)

\section{Control corneal tissue}

The corneal endothelium was evaluated using anti-actin fluorescence staining and confocal microscopy to identify cell outlines as indicated in Methods.

Since it was important to have information on the integrity of the corneal endothelium in donor corneal graft tissue before grafting, preliminary control experiments were performed to compare endothelial cell coverage of excised but non-grafted discs (post-X fixed corneas, see Methods) with
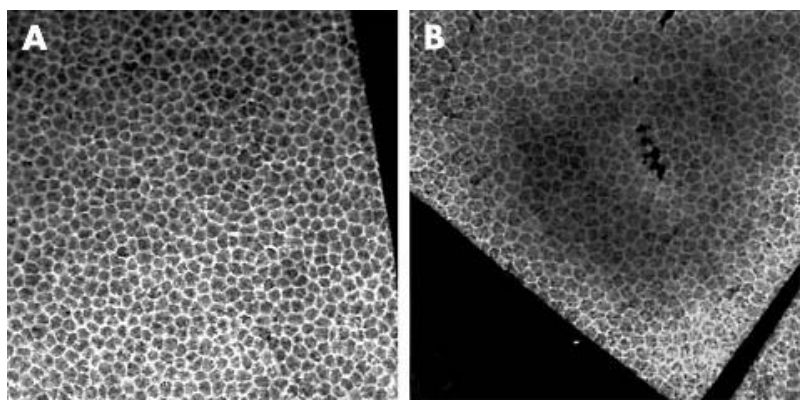

Figure 2 The endothelium in controls. Confocal images of the centre of control pre-X fixed cornea (A) and control post-X fixed cornea (B). Objective $\times 20$. the corneal endothelium of the intact eye (pre- $\mathrm{X}$ fixed corneas, see Methods).

All control pre- $X$ fixed and post- $X$ fixed corneal tissue samples displayed the endothelial monolayer as an almost intact cell sheet with regular hexagonal shaped cells (fig $2 \mathrm{~A}$, $\mathrm{B}$, respectively). Evidence of cell loss was found only at the edge of the post-X fixed corneal buttons, where contact with the forceps occurred during manipulation. In both control pre- $X$ fixed and post- $X$ fixed corneas the posterior surface was covered by at least $90 \%$ of endothelial cells (pre-X fixed corneas: $99 \%(0.8 \%)$ endothelial coverage (mean (SD)); post$X$ fixed corneas: $94 \%$ (4.1\%) endothelial coverage; see fig $3 \mathrm{~A}$ ).

\section{Allogeneic grafts}

In allografts, endothelial integrity was much more variable. One hour after grafting the endothelial monolayer was essentially similar to that in the control corneas, with occasional areas of patchy damage (fig 4A), and an overall coverage of $64 \%$ (SD 13.7\%) (fig 3A). At 24 hours, some endothelial cells had enlarged and spread over the damaged areas, as a result of which some cells had lost their regular hexagonal shape (fig 4B). At 48 hours the grafts coverage was $84 \%$ (SD $12.1 \%$ ) (fig $3 \mathrm{~A}$ ). At 6,10 , and 14 days the cellular pattern remained the same (fig 4C, D, E) and $61 \%$ (SD 24.2\%) (6 days) and 91\% (SD 8.4\%) (10 days) of the area of the graft was covered by endothelium (fig 3A).

At 30 days post-grafting the state of the endothelium more faithfully reflected the clinical status of the graft. The majority of the grafts were rejected (see fig 1), and the mean percentage of remaining endothelium was 32\% (41.8\%) (fig 3A). Completely clear allografts contained regular hexagonal enlarged endothelial cells which were spread over the graft always in contact with some of the neighbouring cells but did not appear to form a contiguous monolayer (fig 4F). Rejected (opacity grade $\geqslant 2$ ) grafts had no endothelium (fig 4G).

At 60 days, no allografted mice retained clear (opacity 0) corneas (100\% of rejection within the 60 day observation period $^{7}$ ) and all such grafts were the mostly devoid of endothelium (fig 4H, I, J), mean coverage being 45\% (40.7\%) (fig 3A).

During this stage of the study it was noted that from 48 hours post-grafting it was difficult to visualise the graft endothelium, owing to the presence of a protein film, which first developed at the graft edge and spread over the entire graft surface (fig 5A, B), covering the endothelium (fig 5C). The protein film stained positively with phalloidin, presumably as a result of actin release from damaged cells including degranulating platelets, and dying endothelial cells. ${ }^{28}$ After several days the film progressively contracted back towards the periphery of the graft (fig 5D), where it was still detectable in some cases up to 2 months after grafting. This retrocorneal protein film or "membrane" could be distinguished from the iris, which stained for actin in a fine reticular pattern (fig 5E). The film was considered to be fibrin based, which was confirmed by immunohistochemistry 

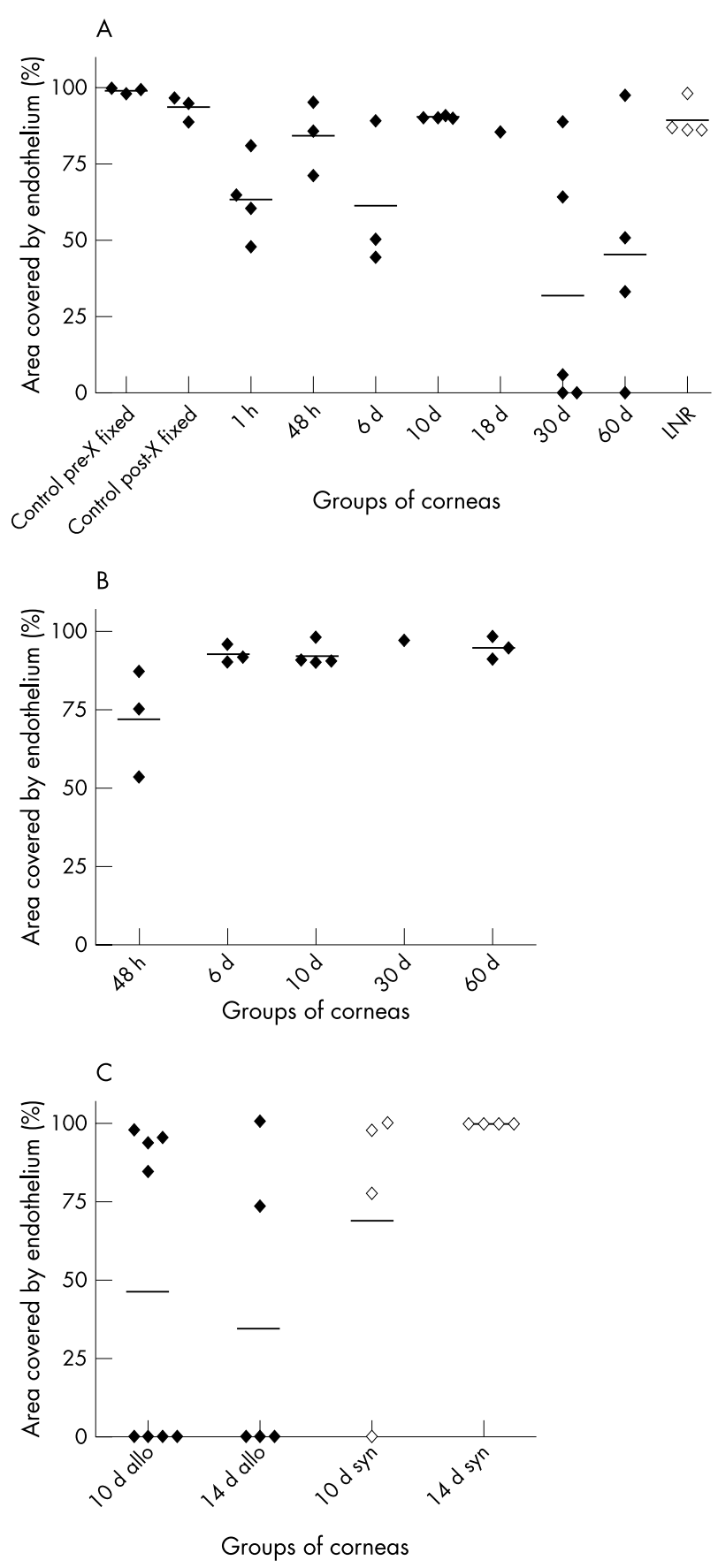

Figure 3 Quantitative analysis of the area covered by the endothelium after allogeneic and syngeneic grafting. Graph showing the area covered by endothelium in control pre- $X$ fixed and post- $X$ fixed corneas, and in allogeneic (A) and syngeneic (B) grafts (continuous suture) in different time points after grafting. Separately is showed the area covered by endothelium in allogeneic and syngeneic grafts where interrupted suture technique was used (C). Each symbol is an individual corneal sample. The lines show the mean values. $h$, hours; $d$, days; LNR, lymph node removal; allo, allogeneic; syn, syngeneic.

(fig 5F, G), and derived from contraction of a coagulated plasmoid aqueous. Corneas from mice taken 48 hours to 10 days post-grafting were therefore treated with tPA before fixation, which proved to be effective in removing the film. However, in corneas taken later than 10 days after grafting, the membrane was resistant to digestion with tPA, presumably because of organisation of the fibrin clot, which as indicated above continued to retract towards the periphery of the graft (fig 5D).
Syngeneic grafts

In syngeneic corneal grafts, the percentage of the covering endothelium did not fall below $54 \%$ at any time. The appearance of syngeneic grafts in the early phases postgrafting ( 1 hour-14 days) were identical to that in allogeneic grafts (figs 6A, B) including the presence of the phalloidin staining protein film. The enlarged endothelial cells however remain unchanged in syngeneic grafts until 60 days post grafting (fig 6C). At 48 hours the area covered by the endothelium was $72 \%$ (SD 17.1\%), at 6 days 93\% (SD 2.9\%), at 10 days $95 \%$ (SD $5.2 \%$ ), at 30 days $97 \%$, and at 60 days it was $95 \%$ (SD 3.7\%) of the graft (fig 3B).

\section{Allografts after lymph node removal}

We have previously shown that removal of the draining lymph node protects corneal allografts from rejection indefinitely. ${ }^{24}$ We presumed therefore that the donor endothelium would remain intact during this time.

Corneal allografts grafts in mice, which had had removal of the submandibular lymph node also showed an intact endothelial cell monolayer, with regular hexagonal shaped cells (fig 7). Endothelial coverage in this group extended to $91 \%(6.7 \%)$ (fig 3A).

Quantitative evaluation of endothelial cell integrity at different time points after grafting (interrupted suture technique)

Some corneas appeared to pass through a phase of transient opacification 10-14 days post-grafting and clear subsequently. This occurred more frequently when the grafts were performed with interrupted sutures than with continuous sutures. ${ }^{7}$ The cause for the transient opacity is not known and one possibility is that the endothelium after grafting goes through the period of dysfunction. The other possibility is that the endothelium is lost and is replaced from the host. To prove if it was one of these reasons, quantitative analysis of the endothelium was performed.

In this study, allogeneic grafts, performed using the interrupted suture technique, were covered at day 10 after grafting by $46 \%$ of endothelium on average (fig 3C). However, this varied greatly from graft to graft and generally adopted two patterns-that is, where the endothelium was almost intact (84-97\% in four grafts) to where there was no endothelium (in four grafts; table 2, fig 3C). By day 14 the average endothelial cell coverage was $34 \%$ of graft area, with complete absence of endothelium in three of five grafts and 73-99\% coverage of endothelium in two out of five grafts.

In syngeneic grafts on day 10, the mean of the covered area was $68 \%$, with one denuded graft and three covered by $77-$ $97 \%$ of endothelium. On day 14, all of the syngeneic grafts were covered by at least $99 \%$ of endothelium (fig 3C).

\section{Correlation of corneal graft opacity with the percentage of remaining corneal graft endothelium}

In currently used scoring systems, ${ }^{7}$ opacity grades $0-4$ are used, and grafts with opacity 2 or greater are considered rejected. However, although the endothelium is the major target for rejection, ${ }^{11}$ the precise relation between endothelial cell loss and opacity level is unclear. For this part of the study, the results of previous quantitative analyses were pooled, regardless of technique or donor mice used, since the opacity grade and the endothelium were correlated and not the technique which induced the opacity.

The results of our study show that, overall, grafts with opacity grades 0 or 1 retained over $80 \%$ endothelial cell coverage, whereas grafts with opacity 2 or above had less than $50 \%$ coverage with endothelium on average (fig 8). However, there was considerable individual variation in this correlation particularly during the first $1-3$ weeks following 


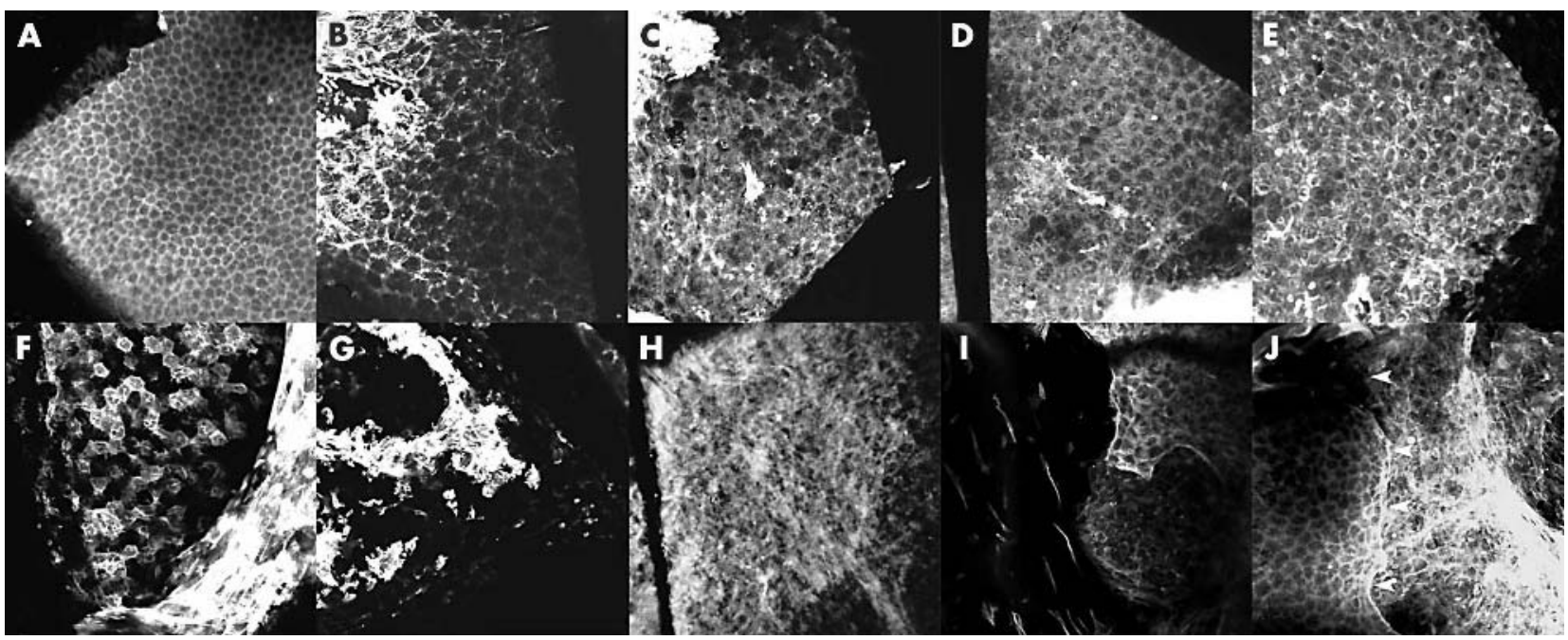

Figure 4 The endothelium in allografts. Confocal images of the endothelium of the allografts 1 hour (A), 24 hours (B), 6 days (C), 10 days (D), 14 days $(E), 30$ days $(F, G)$ and 60 days $(H, I, J)$ after transplantation stained for actin. Opaque grafts (grade $\geqslant 2)(G, H, I, J)$. Clear grafts $(A, B, C, D$, $E, F)$. Image J shows the junction of the host endothelium (left of image) with the rejected donor graft (arrowheads); note absence of endothelial cells on the donor graft (right of image). Objective $\times 20$.

grafting with some corneas clinically graded as 3 or 4 still retaining over $80 \%$ of their endothelium while other corneas graded as 0 or 1 retaining less than $50 \%$ endothelium (fig 8 ). In contrast, corneas graded 3 or 4 , which persisted during 60 days observation period, were consistently devoid of endothelium.

\section{DISCUSSION}

Recent data from experimental work in mice indicate that the corneal endothelium is a major target for graft rejection, while the epithelium is rapidly replaced in both syngeneic and allogeneic grafts. ${ }^{11}$ In fact, early replacement of the donor epithelium with syngeneic epithelium has a protective effect on the donor graft by suppressing the alloimmune response provided the new epithelial layer contains few dendritic cells. ${ }^{10}$ The present report confirms the central position of the endothelium as the target for alloimmune attack and attempts to quantify this response in terms of acceptance or rejection of the graft. The data show that there is early loss of $30-40 \%$ endothelial cells in both syngeneic and allogeneic grafts during the first 48 hours but that recovery of the endothelial monolayer occurs during the first few days by enlargement and spreading of the cells. In syngeneic grafts, this continues to provide a satisfactory covering for the cornea and permits survival of the graft. In long term accepted allogeneic grafts-for instance, in mice after removal of the draining lymph node, ${ }^{24} 29$ a similar situation holds true and the donor endothelium survives. However, in rejected grafts the endothelium is lost. In neither accepted, nor rejected or in syngeneic grafts was there evidence of replacement by host endothelium.

The present quantitative analysis of corneal endothelial coverage also allowed an evaluation of the clinical grading system. Clinically grafts are graded using a scoring system

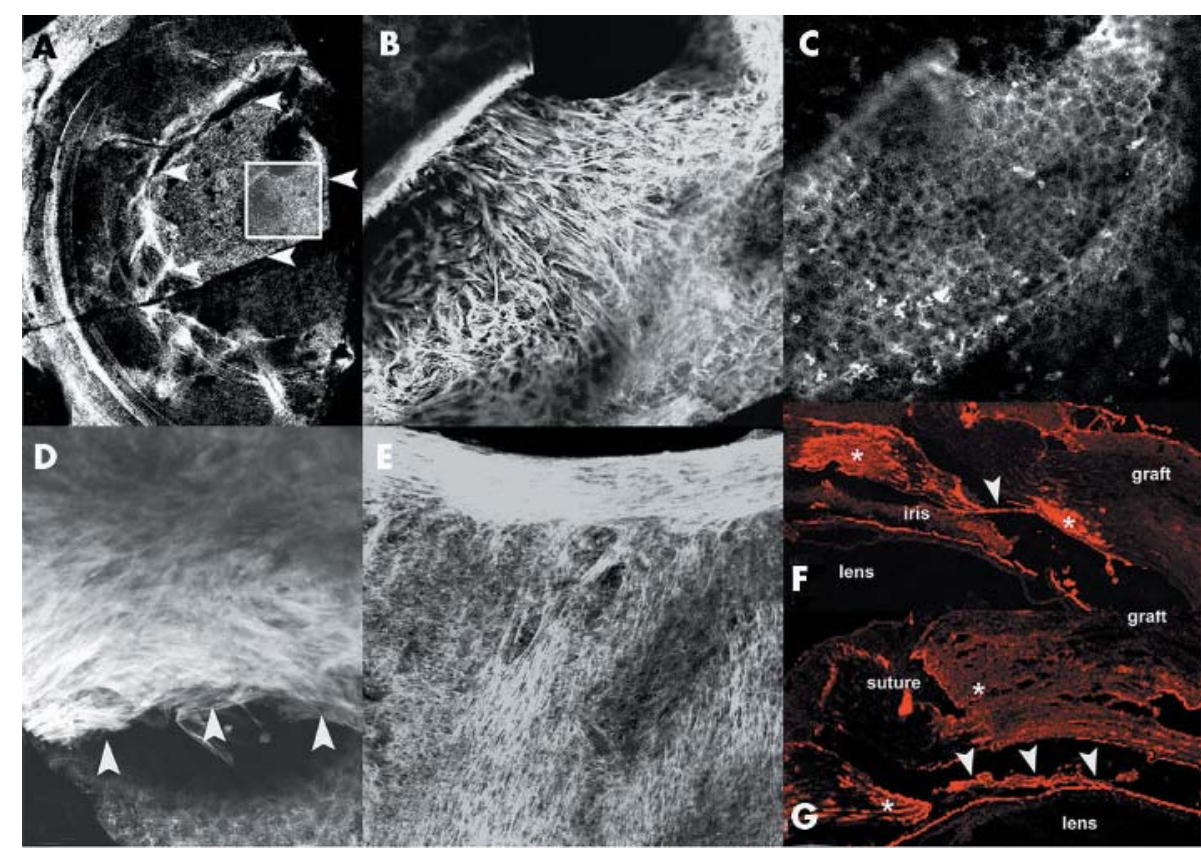

Figure 5 Confocal images of posterior surface of corneal allografts demonstrating fibrous/fibrinous membrane. Four days post-grafting. Low magnification $(\times 4)$ images demonstrating membrane (arrowheads) (A). Higher resolution image $(\times 20)$ of region outlined in inset of $(A)$ and staining detail of the membrane (B). Same field as (B) focused on the endothelial monolayer (C). 10 days post grafting showing the membrane contracted down to graft-host junction (arrowheads) (D). Actin staining of iris surface showing light reticular pattern of surface filaments $(E)$. $(F, G)$ Immunohistological pictures of a frozen section of the eye 24 hours and 4 days post grafting respectively, positive staining for fibrinogen in red. Note fibrin membrane on surface of lens (arrowheads) and prominent fibrin staining at wound edge (asterisks). 


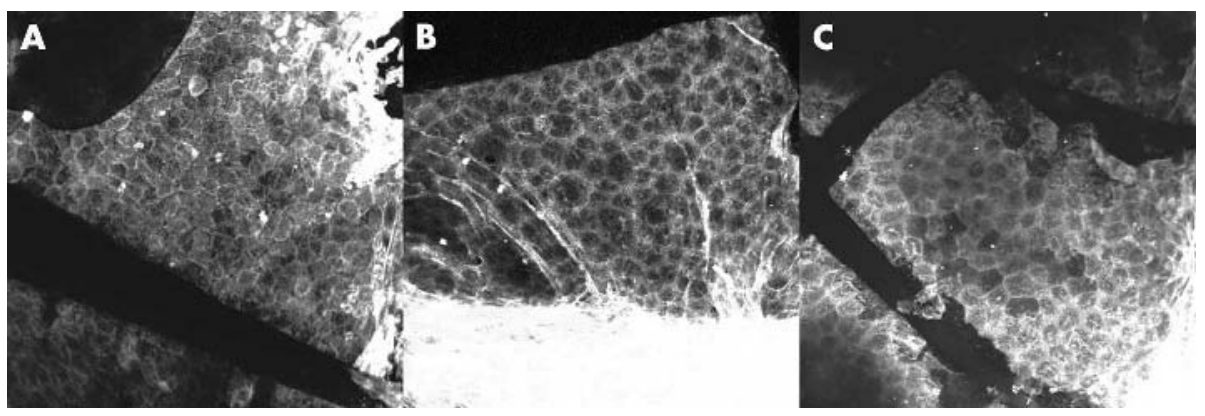

Figure 6 The endothelium in syngeneic grafts. Confocal images of the endothelium of the syngeneic grafts 48 hours (A), 14 days (B), and 60 days (C) post-grafting stained for actin. Objective $\times 20$

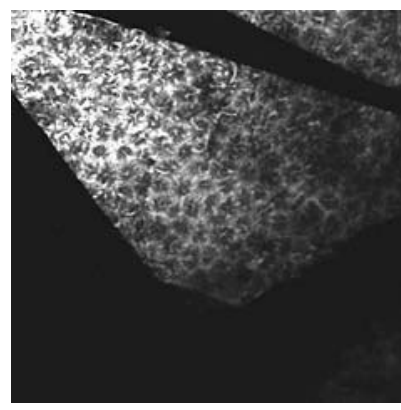

Figure 7 The endothelium in allografts after lymph node removal. Confocal image of the endothelium of the accepted allograft in mouse after lymph node removal 60 days postgrafting stained for actin. Objective $\times 20$

based predominantly on the relative opacification of the cornea. In the present study, there was a statistically good agreement between the percentage surviving endothelial monolayer and the grade of opacity. However, the relation was not consistent and some grafts during the early alloimmune response presented with apparent opacity grades equating to rejection (grade $\geqslant 2$ ) while retaining a good $(>84 \%)$ endothelial cell coverage. This applies also for syngeneic grafts, which frequently achieve a grade of 2 or more in the first 2 weeks after grafting and therefore cannot, during this period, be legitimately defined as "rejected."

Only in grafts during the later stages of observation was clinical "rejection" (grade $\geqslant 2$ ) consistently associated with an endothelial cell loss more than $49 \%$ ( six of seven). Thus, it is clear that clinical graft rejection, when considered as an irreversible event, can only reliably be determined if both the level of opacification and a sufficient time of observation are taken into account. In previous studies these are the precise criteria, which Streilein's group has adopted (opacity grade $\geqslant 2$ evaluated at 8 weeks post graft) and in order to allow interstudy comparison of data we would also recommend this approach.

This raises the question of what the early opacification of the cornea represents since the endothelium at this stage may morphologically remain well preserved. Opacification of the cornea can occur for many reasons including reasons unrelated to the survival of the endothelium. Thus, oedema, scarring, cellular infiltration of the stroma among other causes may induce degrees of opacity. At least some of these may occur during corneal graft rejection. However, we have not previously found stromal cellular infiltration to contribute greatly to corneal opacification during graft rejection. ${ }^{30}$ We have argued that transient opacification may occur in the cornea during the process of rejection because of the alloimmune response. At this time, the endothelium is under attack and possibly dysfunctional but still has the potential for recovery. The use of Kaplan-Meier survival curves for presenting data on graft rejection thus are liable to misinterpretation during the early phase of study since they do not allow for the differentiation of the process of rejection (with the potential for recovery) from irreversible rejection when the endothelium has been lost. We argue that presentation of the data as "opacity curves" provides more useful information. ${ }^{7}$

The possibility that the endothelium can recover leads to questions of how the endothelium suffers damage during rejection. Previously it has been considered that cells targeted for alloimmune attack incur this damage through the activity of cytotoxic T cells. ${ }^{31}$ While induction of these cells is not disputed, they are regarded as not essential for the process of rejection. In contrast, the relative importance of CD4 T cells has gained prominence ${ }^{32-35}$ as have the effects of cells involved in innate immune responses such as natural killer (NK) cells ${ }^{36}$ and macrophages. ${ }^{30}{ }^{37}$ We have previously shown

\begin{tabular}{|c|c|c|c|c|c|c|}
\hline \multirow[b]{2}{*}{ Groups of corneas } & \multirow{2}{*}{$\begin{array}{l}\text { Opacity at } \\
\text { day } 10\end{array}$} & \multicolumn{5}{|c|}{ Opacity at the day of removal } \\
\hline & & 0 & 1 & 2 & 3 & 4 \\
\hline Day 10 syngeneic & - & $Y, Y$ & & Y & $\mathrm{N}$ & \\
\hline Day 10 allogeneic & - & & Y & $\mathrm{N}, \mathrm{N}$ & $\mathrm{N}$ & $N, Y, Y, Y$ \\
\hline \multirow{5}{*}{ Day 14 syngeneic } & 1.5 & Y & & & & \\
\hline & 1.5 & Y & & & & \\
\hline & 0 & Y & & & & \\
\hline & 2 & Y & & & & \\
\hline & 4 & & Y & & & \\
\hline \multirow[t]{6}{*}{ Day 14 allogeneic } & 2 & Y & & & & \\
\hline & 2 & Y & & & & \\
\hline & 4 & & Y & & & \\
\hline & 3 & & & & $\mathrm{~N}$ & \\
\hline & 4 & & & & & $\mathrm{~N}$ \\
\hline & 4 & & & & & $\mathrm{~N}$ \\
\hline
\end{tabular}




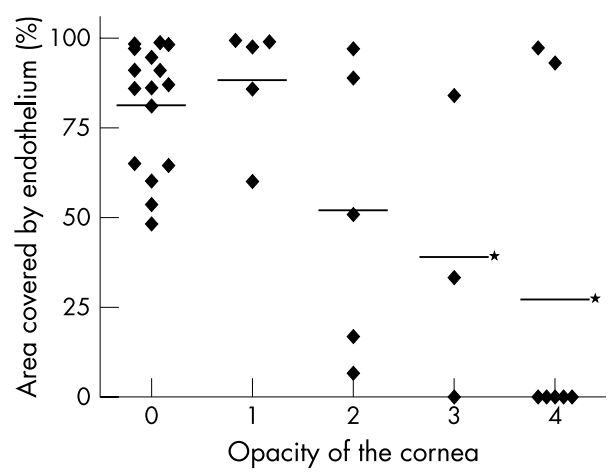

Figure 8 Quantitative analysis of the area covered by endotheliumopacity evaluation. Graph showing the area covered by endothelium in corneas with different grades of clinical opacity (0-4). Each symbol is an individual corneal sample. The lines show the mean values opacity 3 and 4 differ from opacity 0 at a statistical significance of $p<0.05$ (*). Both the interrupted and continuous suture techniques were used.

that macrophages represent a major cell population in corneal graft rejection and are present from an early time (hours/days following grafting). ${ }^{30}$ How do effector cells of the innate and adaptive immune response gain access to the endothelium? Previously it has been considered that leucocytic cells reach their target by infiltration via the limbus and the stroma and there is evidence of significant cell infiltration at these sites during rejection. ${ }^{30}{ }^{36}$ However, there are several barriers for invading leucocytes en route to the endothelium via the limbus/stroma and, overall, this would appear to be a slow and inefficient mechanism. An alternative route for cells to gain access is from the iris vessels via the anterior chamber since it has previously been shown that there is a massive infiltration of macrophages in the iris after corneal grafting. ${ }^{38}$ These cells need to traverse the chamber and must do so by crawling on surfaces or through matrices. This study has shown that the anterior chamber is filled with a fibrin containing clot almost immediately after grafting and this provides an excellent conduit for cell migration. Thus, myeloid and lymphoid cells emigrating from the iris vessels can rapidly cross the anterior chamber through the fibrin clot and attach to the endothelium where they can cause damage. The fibrin clot itself may be promoted by the procoagulant myeloid cells. Fibrin clots occur in both syngeneic and allogeneic grafts but the response is greater and more sustained in allografts and is probably driven by $\mathrm{T}$ cell cytokine production. The strong phalloidin staining, and thus presumed presence of actin within the fibrin clots, is likely to be a measure of actin release from damaged cells and itself may contribute to the continued endothelial cellular damage as has been shown intravascularly in actin containing sera. ${ }^{39}$

It would seem therefore that the corneal graft survival is dependent on continuing viability of the donor endothelium which may undergo attack from both innate and adaptive immune mechanisms. The endothelium has the potential to repel such attach (for example, Fas-FasL interaction ${ }^{40}$ ) and the anterior chamber itself is an immune privileged microenvironment. While some degree of endothelial cell loss during this process may occur, it would appear from this study that in the mouse at least, a minimum of $48 \%$ donor endothelial cell survival is required.

\section{ACKNOWLEDGEMENTS}

Supported by University of Aberdeen Development Trust (UK).

\section{Authors' affiliations}

J Plskova, L Kuffova, J V Forrester, Department of Ophthalmology, University of Aberdeen, Scotland, UK
J Plskova, M Filipec, Department of Ophthalmology, Charles University, Prague, Czech Republic

J PIskova, V Holan, Institute of Molecular Genetics, Academy of Science, Prague, Czech Republic

\section{REFERENCES}

1 The Collaborative Corneal Transplantation Studies Research Group. The collaborative corneal transplantation studies (CCTS): effectiveness of histocompatibility matching in high-risk corneal transplantation. Arch Ophthalmol 1992;110:1392-403.

2 Niederkorn JY. The immune privilege of corneal allografts. Transplantation 1999;67:1503-8.

3 Niederkorn JY, Mellon J. Anterior chamber-associated immune deviation promotes corneal allograft survival. Invest Ophthalmol Vis Sci 1996:37:2700-7.

4 Sonoda Y, Streilein JW. Orthotopic corneal transplantation in mice-evidence that the immunogenetic rules of rejection do not apply. Transplantation 1992;54:694-704.

5 Katami M, Madden PW, White DJ, et al. The extent of immunological privilege of orthotopic corneal grafts in the inbred rat. Transplantation 1989;48:371-6.

6 Williams KA, Muehlberg SM, Lewis RF, et al. How successful is corneal transplantation? A report from the Australian corneal graft register. Eye 1995;9:219-27.

7 Plskova J, Kuffova L, Holan V, et al. Evaluation of corneal graft rejection in a mouse model. Br J Ophthalmol 2002;86:108-13.

8 Williams KA, Coster DJ. Rethinking immunological privilege: implications for corneal and limbal stem cell transplantation. Mol Med Today 1997;3:495-501

9 Hori J, Joyce NC, Streilein JW. Immune privilege and immunogenicity reside among different layers of the mouse cornea. Invest Ophthalmol Vis Sci 2000;41:3032-42.

10 Hori J, Streilein JW. Role of Recipient Epithelium in Promoting Survival of Orthotopic Corneal Allografts in Mice. Invest Ophthalmol Vis Sci 2001;42:720-6.

11 Hori J, Streilein JW. Dynamics of donor cell persistence and recipient cell replacement in orthotopic corneal allografts in mice. Invest Ophthalmol Vis Sci 2001;42:1820-8.

12 Engelmann K, Bednarz J, Bohnke M. Endothelial cell transplantation and growth behavior of the human corneal endothelium. Ophthalmologe 1999;96:555-62.

13 Olsen EG, Davanger M. The healing of human corneal endothelium. An in vitro study. Acta Ophthalmol (Copenh) 1984;62:885-92.

14 Senoo T, Joyce NC. Cell cycle kinetics in corneal endothelium from old and young donors. Invest Ophthalmol Vis Sci 2000;41:660-7.

15 Senoo T, Obara Y, Joyce NC. EDTA: a promoter of proliferation in human corneal endothelium. Invest Ophthalmol Vis Sci 2000;41:2930-5.

16 Hirsch M, Faure JP, Marquet O, et al. Regeneration of corneal endothelium in the rabbit: microscopic study and relation with corneal thickness. Arch Ophtalmol Rev Gen Ophtalmol 1975;35:269-78.

17 Minkowski JS, Bartels SP, Delori FC, et al. Corneal endothelial function and structure following cryo-injury in the rabbit. Invest Ophthalmol Vis Sci 1984;25:1416-25.

18 Petroll WM, Jester JV, Bean J, et al. Labeling of cycling corneal endothelial cells during healing with a monoclonal antibody to the Ki67 antigen (MIB-1). Cornea 1999;18:98-108

19 Tuft SJ, Williams KA, Coster DJ. Endothelial repair in the rat cornea. Invest Ophthalmol Vis Sci 1986;27:1199-204.

20 Imaizumi T. Movement of corneal endothelium after penetrating keratoplasty. Observation of sex chromatin as a cell marker. Nippon Ganka Gakkai Zasshi 1990;94:928-36

21 Nakahori Y, Katakami C, Yamamoto M. Corneal endothelial cell proliferation and migration after penetrating keratoplasty in rabbits. Jpn J Ophthalmol 1996;40:271-8.

22 Joo C-K, Green WR, Pepose JS, et al. Repopulation of denuded murine Descemet's membrane with life-extended murine corneal endothelial cell as a model for corneal cell transplantation. Graefes Arch Clin Exp Ophthalmol 2000;238:174-80.

23 She SC, Steahly LP, Moticka EJ. A method for performing full-thickness, orthotopic, penetrating keratoplasty in the mouse. Ophthalmic Surg 1990;21:781-5.

24 Plskova J, Duncan L, Holan V, et al. The immune response to corneal allograft survival requires a site specific draining lymph node. Transplantation 2002;73:210-15

25 Danjo Y, Gipson IK. Actin 'purse string' filaments are anchored by Ecadherin-mediated adherens junctions at the leading edge of the epithelial wound, providing coordinated cell movement. J Cell Sci 1998; 1 11:3323-31.

26 Petroll WM, Hsu JKW, Bean J, et al. The spatial organization of apical junctional complex-associated proteins in feline and human corneal endothelium. Curr Eye Res 1999;18:10-19.

27 Wolvers DA, Coenen-de Roo CJ, Mebius RE, et al. Intranasally induced immunological tolerance is determined by characteristics of the draining lymph nodes: studies with OVA and human cartilage gp-39. J Immunol 1999; 162:1994-8.

28 Haddad JG, Harper KD, Guoth M, et al. Angiopathic consequences of saturating the plasma scavenger system for actin. Proc Natl Acad Sci USA 1990;87:1381-5 
29 Yamagami S, Dana MR. The critical role of lymph nodes in corneal alloimmunization and graft rejection. Invest Ophthalmol Vis Sci 2001;42:1293-8

30 Kuffova L, Lumsden L, Vesela V, et al. Kinetics of leukocyte and myeloid cell traffic in the murine corneal allograft response. Transplantation 2001;72:1292-8.

31 Sano Y, Streilein JW, Ksander BR. Detection of minor alloantigen-specific cytotoxic T cells after rejection of murine orthotopic corneal allografts: evidence that graft antigens are recognized exclusively via the "indirect pathway". Transplantation 1999:68:963-70.

32 Ksander BR, Sano Y, Streilein JW. Role of donor-specific cytotoxic T cells in rejection of corneal allografts in normal and high-risk eyes. Transpl Immunol 1996;4:49-52.

33 Hegde S, Niederkorn JY. The role of cytotoxic T lymphocytes in corneal allograft rejection. Invest Ophthalmol Vis Sci 2000;41:3341-7.

34 Sano Y, Ksander BR, Streilein JW. Analysis of primed donor-specific T cells in recipient mice bearing orthotopic corneal allografts. Transplantation 2000;70:1302-10.
35 Sano Y, Ksander BR, Streilein JW. Langerhans cells, orthotopic corneal allografts, and direct and indirect pathways of T-cell allorecognition. Invest Ophthalmol Vis Sci 2000;41:1422-31.

36 Larkin DF, Calder VL, Lightman SL. Identification and characterization of cells infiltrating the graft and aqueous humour in rat corneal allograft rejection. Clin Exp Immunol 1997;107:381-91.

37 Slegers TPA, Torres PF, Broersma L, et al. Effect of macrophage depletion on immune effector mechanisms during corneal allograft rejection in rats. Invest Ophthalmol Vis Sci 2000;41:2239-47.

38 Krause L, Coupland SE, Hoffmann F. The behaviour of ED1- and ED2-positive cells in the rat iris and choroid following penetrating keratoplasty and cyclosporin A therapy. Graefes Arch Clin Exp Ophthalmol 1996;234:S1 49-58

39 Erukhimov JA, Tang Zi-L, Johnson BA, et al. Actin-containing sera from patients with adult respiratory distress syndrome are toxic to sheep pulmonary endothelial cells. Am J Respir Crit Care Med 2000;162:288-94.

40 Ferguson TA, Griffith TS. A vision of cell death: insights into immune privilege Immunol Rev 1997;156:167-84. 